\title{
THE METABOLIC OUTCOME OF SINGLE ANASTOMOSIS SLEEVE ILEAL OPERATION
}

\author{
By
Hatem M. El-Mahdy, Ashraf A. Abd El-Monem, Abd El-Fatah M. Saied and Tarek A. El-Dahshan* \\ Department of General Surgery and Clinical Pathology*, Faculty of Medicine, Al-Azhar \\ University Cairo, Egypt \\ Corresponding Author: Hatem Mohamed Elmahdy, \\ Mobile: (+20) 01020243060, E-mail: tim22he@ gmail.com
}

\begin{abstract}
Background: Obesity is considered a health hazard for metabolic disorders including diabetes mellitus (DM), dyslipidemia, hypertension and other related comorbidities. Laparascopic sleeve gastrectomy is considered more efficient bariatric procedure for weight loss compared with nonsurgical interventions. Single anastomosis sleeve ileal (SASI) bypass has been established as a new bariatric and metabolic procedure.
\end{abstract}

Objective: To show metabolic disorders (DM, hyperlipidemia and hypertension) after SASI operation, and to detect short outcomes as regard weight loss and to assess complications as malnutrition.

Patients and Methods: An interventional prospective study was carried at Bab Alshaariya university hospital, Cairo from May 2019 till November 2019.This study was conducted on 20 patients with body mass index $(\mathrm{BMI}) \geq 48 \mathrm{~kg} / \mathrm{m} 2$ underwent SASI bypass surgery and were followed for 6 months postoperatively. Changes in BMI, excess weight loss (EWL), routine lab investigations (FPG, HbAIC, triglyceride, cholesterol, HDL), and comorbidities improvement were recorded on six months follow-up post operation.

Results: The main results of the study revealed that mean \pm SD age of the patients at the time of operation were $38.3 \pm 3.61$, mean BMI was $48.7 \pm 7.6,25 \%$ of cases were males and $75 \%$ were females. $65 \%$ of cases were diabetic, $40 \%$ hyperlipidmic, and $30 \%$ were hypertensive patients. There was a high significant difference between pre and post-surgery as regard FPG, HbAIC, triglyceride, cholesterol, HDL and LDL. There was a high significant difference between before and after surgery as regard BMI. Mean amount of blood loss was $76.1 \pm 15.2$ with a range of 50-150ml. During surgery, leak during methylene blue test was in $5 \%$ of cases, and no post-operative stenosis in cases.

Conclusion: SASI bypass is an effective bariatric and metabolic surgery for achieving satisfactory weight loss in patients suffering other metabolic disorders with minimal surgical complications.

Key words: Bariatric surgery, Obesity, BMI, Metabolic disorders and SASI bypass.

\section{INTRODUCTION}

Obesity is a global epidemic condition characterized by an excess of body adiposity and for practical reasons is commonly measured by BMI, an expression of body weight as a nonlinear function of height. A BMI $>30 \mathrm{~kg} / \mathrm{m} 2$ indicates the presence of obesity; when
BMI exceeds $40 \mathrm{~kg} / \mathrm{m} 2$, the subject is regarded as morbidly obese (Olmi et al., 2019). Obesity has a risk factor for diabetes mellitus, dyslipidemia and cardiovascular disease, predictor for renal failure, inflammation and much other comorbidity (Andersson, 2015). 
The rising obesity prevalence, along with high numbers of non-responders to medical weight-reduction programs, has led to the evolution and success of bariatric surgery. Although this treatment was initially conceived purely for weight loss, bariatric surgery has since evolved into a treatment for health gain (Abouzeid et al., 2019).

Bariatric operations have traditionally been categorized as restrictive (band and sleeve), malabsorptive biliopancreatic diversion (BPD) with duodenal switch (DS), or combined restrictive and malabsorptive Roux-en-Y gastric bypass (RYGB) procedures. Gastric banding and sleeve gastrectomy only alter stomach anatomy, whereas RYGB and BPD involve anatomic alterations of both the stomach and the small bowel (Angrisani et al., 2015).

Furthermore, the BPD and DS result in significantly greater remission of metabolic comorbidities such as T2DM, compared with other interventions with equivalent weight loss (Carbajo et al., 2017).

The criteria of BMI over $40 \mathrm{~kg} / \mathrm{m} 2$ were based on risk-benefit evidence (risk of obesity vs. surgical risk-benefit) at the time when most operations were not being done laparoscopic ally. So, adoption of the laparoscopic approach to bariatric surgery and safer anesthetic techniques in these patients have reduced surgical risk significantly (Augustin and Rogess, 2017).

Great advancements made in the development of bariatric surgical techniques have resulted in new techniques such as the single anastomosis sleeve ileal bypass (SASI) procedure, which emerged as a novel metabolic and bariatric surgery based on Santoro's operation, in which sleeve gastrectomy is followed by gastroileal loop anastomosis (Salama et al., 2017).

A professional organizations and government agencies that recognize the role of bariatric surgery as a treatment of T2DM and advocate the use of diseasebased criteria beyond just BMI. These guidelines are contributing to transforming a weight loss intervention into a surgical practice shaped around the goal to improve metabolism and reduce cardiometabolic risk. Such concept and practice is referred to as "metabolic surgery (Swanström and Beard, 2018).

The present study aimed to detect metabolic disorders including DM, hyperlipidemia and hypertension after SASI operation. Also to demonstrate short outcomes as regard weight loss and to assess complications as malnutrition.

\section{PATIENTS AND METHODS}

An interventional prospective study was conducted on 20 patients (15 female and 5 male) for different metabolic outcome after single anastomosis sleeve ileal (SASI) operation, at General Surgery Unit, Bab Alshaariya University Hospital, Cairo. This study was carried out from May 2019 till November 2019.

All subjects signed informed written consents after explanation of the aim of the study and the study details. The study was approved by the ethical committee of Al Azhar Faculty of Medicine.

Inclusion criteria: $\mathrm{BMI} \geq 35$ with metabolic disorders and $\mathrm{BMI} \geq 40$ with sweet eaten 
Exclusion criteria: Patients of previous bariatric surgery and patients were not fit to surgery.

All patients had preoperative evaluation including full history taking, clinical examination, and lab investigation including complete blood picture, ferritin level, fasting plasma glucose,HBA1c, lipid profile, TSH level, and serum calcium. In addition, routine gastroscope was performed, and radiological investigation as abdominal us to exclude gall stones and degree of fatty liver.

The operation was done under general anesthesia, and patient was in french position. The procedure started using optical trocar and devascularization of the greater curvature of the stomach with harmonic scalpel (Ultracision, Ethicon Endo-Surgery, Inc.). The stomach was tabularized, with a linear stapler. A stapled isoperistaltic side-to-side to the anterior wall of the antrum of the stomach just $3 \mathrm{~cm}$ away from the pylorus with a linear stapler (Echelon 45). The staple defect was closed with a two-layer running 3/0 polydioxanone suture. The transected stomach was then removed through the 12 -mm left midclavicular port. The anastomosis was tested for water tightness with methylene blue test.

All patients had monitoring as weight loss, associated complications and same routine lab investigation. Thrombosis prophylaxis (enoxaparin 40 once daily) continued from the first postoperative day up to 4 weeks. Before discharge, gastrografin swallow X-ray study was routinely performed between the second and third postoperative day, to exclude the leak.

Proton pump inhibitor was
for postoperatively. Patients were reviewed as outpatients 2 weeks postoperatively, then every month for 6 months. The primary outcomes were the percent of excess weight loss (\% EWL), resolution of diabetes and improvement of comorbidity. The percent of EWL was calculated as follows: (preoperative weight follow up weight)/ preoperative excess weight $\times 100$. Secondary outcomes were postoperative complications and postoperative nutritional status.

\section{Statistical Analysis:}

Results were tabulated and statistically analyzed by using a personal computer using version 20 (SPSS Inc., Chicago, IL, USA). Data were expressed as number and percentage for qualitative variable, while they were expressed as mean \pm SD for quantitative variables. For comparing change in continuous variable over time we used repeated measure ANOVA followed by post-hoc test, $\mathrm{P}<0.05$ was considered statistically significant. 


\section{RESULTS}

Mean age of the patients at the time of operation were $38.3 \pm 3.61$, mean $\mathrm{BMI}$ was $48.7 \pm 7.6,25 \%$ of cases were males and $75 \%$ were females. Moreover, $65 \%$ of cases were diabetic, $40 \%$ had hyperlipidemia and $30 \%$ were hypertensive patients (Table 1).

Table (1): Baseline data and Comorbidities distribution in the studied Cases

\begin{tabular}{|c|c|c|}
\hline Variables Time & \multicolumn{2}{|c|}{$(\mathrm{N}=\mathbf{2 0})$} \\
\hline \multicolumn{3}{|l|}{ Age (Years) } \\
\hline $\begin{array}{l}\text { Mean } \pm \text { SD } \\
\text { Range }\end{array}$ & \multicolumn{2}{|c|}{$\begin{array}{l}38.3 \pm 3.61 \\
(32-47)\end{array}$} \\
\hline \multicolumn{3}{|l|}{ BMI $\left(\mathrm{Kg} / \mathrm{m}^{2}\right)$} \\
\hline $\begin{array}{l}\text { Mean } \pm \text { SD } \\
\text { Range }\end{array}$ & \multicolumn{2}{|c|}{$\begin{array}{l}48.7 \pm 7.6 \\
(39-54)\end{array}$} \\
\hline & No. & $\%$ \\
\hline \multicolumn{3}{|l|}{ Gender } \\
\hline Female & 15 & 75 \\
\hline Male & 5 & 25 \\
\hline \multicolumn{3}{|l|}{ DM } \\
\hline Yes & 13 & 65 \\
\hline No & 7 & 35 \\
\hline \multicolumn{3}{|l|}{ Hyperlipidemia } \\
\hline Yes & 8 & 40 \\
\hline $\mathrm{No}$ & 12 & 60 \\
\hline \multicolumn{3}{|l|}{ Hypertension } \\
\hline Yes & 6 & $(30 \%)$ \\
\hline No & 14 & $(70 \%)$ \\
\hline
\end{tabular}

There was high significant difference between before and after surgery as regard FpG mean values were 169.2 \pm 7 4.2, $109.5 \pm 11.8$ and $101 \pm 9$. Pre operatively, $3 \mathrm{~m}$ and $6 \mathrm{~m}$ post operatively, respectively. HBA1c mean values were $9.9 \% \pm 2.7 \%$, $6.1 \% \pm 0.7 \%$ and $5.7 \% \pm 0.8 \%$ pre operatively, $3 \mathrm{~m}$ and $6 \mathrm{~m}$ post operatively, respectively. Triglycerides mean values were $2.7 \pm 0.7,1.4 \pm 0.6$, and $1.1 \pm 0.2$ pre operatively, $3 \mathrm{~m}$ and $6 \mathrm{~m}$ post operatively, respectively. Cholesterol mean values were $6.9 \pm 1.8,4.6 \pm 0.9$ and $3.9 \pm 1.2$ for pre operatively, $3 \mathrm{~m}$ and $6 \mathrm{~m}$ post operatively, respectively. HDL mean values were $1.2 \pm 0.9,2.3 \pm 0.8$ and $2.5 \pm$ 1.9 pre operatively, $3 \mathrm{~m}$ and $6 \mathrm{~m}$ post operatively, respectively. LDL mean values were $4.9 \pm 1.9,2.5 \pm 0.8,2.2 \pm 0.9$ pre operatively, $3 \mathrm{~m}$ and $6 \mathrm{~m}$ post operatively, respectively. Moreover, there was no significant difference between before and after surgery as regard albumin (mean values were $3.84 \pm 0.73,3.86 \pm$ 0.71 and $3.9 \pm 0.71$ for pre operatively, $3 \mathrm{~m}$ and $6 \mathrm{~m}$ post operatively, respectively). $\mathrm{Hb}$ mean values were $14.0 \pm 1.01,13.82 \pm$ 1.22 and $14.39 \pm 1.38$ pre operatively, $3 \mathrm{~m}$ and $6 \mathrm{~m}$ post operatively, respectively. $\mathrm{Ca}$ mean values were $8.35 \pm 0.82,8.55 \pm 0.77$ and $8.95 \pm 0.94$ pre operatively, $3 \mathrm{~m}$ and $6 \mathrm{~m}$ post operatively, respectively. PTH hormone mean values were $15.4 \pm 5.2$, $16.2 \pm 3.4$ and $17.85 \pm 4.7$ pre operatively, 
$3 \mathrm{~m}$ and $6 \mathrm{~m}$ post operatively, respectively. Vit D mean values were $83.45 \pm 66.37$, $107.75 \pm 80.22$ and $119.85 \pm 73.9$ pre operatively, $3 \mathrm{~m}$ and $6 \mathrm{~m}$ post operatively, respectively. Ferritin mean values were $83.45 \pm 66.37,107.75 \pm 80.22$ and 119.85 \pm 73.9 pre operatively, $3 \mathrm{~m}$ and $6 \mathrm{~m}$ post operatively, respectively (Table 2).

Table (2): Different parameters pre and postoperatively in SASI

\begin{tabular}{|c|c|c|c|}
\hline Variable $\longrightarrow$ Time & $\begin{array}{c}\text { Pre- } \\
\text { operatively }\end{array}$ & $\begin{array}{c}3 \text { months } \\
\text { post } \\
\text { operatively }\end{array}$ & $\begin{array}{c}6 \text { months } \\
\text { post } \\
\text { operatively }\end{array}$ \\
\hline \multicolumn{4}{|l|}{ FpG (mg/dl) } \\
\hline Mean \pm SD & $169.2 \pm 74.2$ & $109.5 \pm 11.8$ & $101 \pm 9.8$ \\
\hline \multicolumn{4}{|l|}{ HbA1c (\%) } \\
\hline Mean \pm SD & $9.9 \% \pm 2.7 \%$ & $6.1 \% \pm 0.7 \%$ & $5.7 \pm 0.8 \%$ \\
\hline \multicolumn{4}{|l|}{ Triglycerides ( mmol/L) } \\
\hline Mean \pm SD & $2.7 \pm 0.7$ & $1.4 \pm 0.6$ & $1.1 \pm 0.2$ \\
\hline \multicolumn{4}{|l|}{ Cholesterol ( $\mathrm{mmol} / \mathrm{L})$} \\
\hline Mean \pm SD & $6.9 \pm 1.8$ & $4.6 \pm 0.9$ & $3.9 \pm 1.2$ \\
\hline \multicolumn{4}{|l|}{ HDL (mmol/L) } \\
\hline Mean \pm SD & $1.2 \pm 0.9$ & $2.3 \pm 0.8$ & $2.5 \pm 1.9$ \\
\hline \multicolumn{4}{|l|}{ LDL ( mmol/L) } \\
\hline Mean \pm SD & $4.9 \pm 1.9$ & $2.5 \pm 0.8$ & $2.2 \pm 0.9$ \\
\hline \multicolumn{4}{|l|}{ Albumin (g/dl) } \\
\hline $3.84 \pm 0.73$ & $3.86 \pm 0.71$ & $3.9 \pm 0.71$ & 0.9643 \\
\hline \multicolumn{4}{|l|}{$\mathrm{Hb}(\mathrm{g} / \mathrm{dl})$} \\
\hline $14.0 \pm 1.01$ & $13.82 \pm 1.22$ & $14.39 \pm 1.38$ & 0.3225 \\
\hline \multicolumn{4}{|l|}{ Ca (mg/dl) } \\
\hline $8.35 \pm 0.82$ & $8.55 \pm 0.77$ & $8.95 \pm 0.94$ & 0.0826 \\
\hline \multicolumn{4}{|l|}{ Parathrmon H.(pg/ml) } \\
\hline $15.4 \pm 5.2$ & $16.2 \pm 3.4$ & $17.85 \pm 4.7$ & 0.2225 \\
\hline \multicolumn{4}{|l|}{ Vit D (ng/ml) } \\
\hline $35.1 \pm 10.0$ & $36.85 \pm 7.43$ & $39.4 \pm 7.4$ & 0.27095 \\
\hline
\end{tabular}

The complications of the studied cases during surgery leak during methylene blue test was in $5 \%$ of cases and post- operative bleeding was in $10 \%$ of cases and biliary gastritis was in $15 \%$ (Table 3).

Table (3): Complications of the studied cases

\begin{tabular}{|l|c|c|}
\hline \multicolumn{1}{|c|}{ Variable } & \multicolumn{2}{c|}{ (N=20) } \\
\hline \multicolumn{2}{|c|}{ No. } \\
\hline During surgery & 1 & \% \\
\hline Leak during Mthylene blue test & 0 & 0.0 \\
Convert to open & \multicolumn{2}{|}{} \\
\hline Post-operative & 2 & 10.0 \\
\hline Bleeding & 0 & 0.0 \\
Stenosis & 3 & 15.0 \\
Biliary gastritis & 0 & 0.0 \\
Leak &
\end{tabular}




\section{DISCUSSION}

Obesity has become a pandemic and has received increasing attention over the past decades for the implications it carries in the development of numerous chronic diseases. In the last 30 years, the average BMI has increased at a rate of $0.4 \mathrm{~kg} / \mathrm{m} 2$ per decade worldwide (Okereke et al., 2019). Such a procedure maintains the normal pathway of food, allowing only a small percentage of ingested food to be absorbed, while the majority of food is bypassed directly into the ileum and induces the metabolic effect of the procedure. In addition, it has the advantages of being associated with minimal postoperative nutritional complications and allows the complete visualization of biliary system using endoscopy (Tarek et al., 2015).

A possible explanation of the mechanism of action of the SASI bypass was devised by Mahdy et al. (2019) who reported that, patients who undergo the SASI bypass eat less food because they experience early satiety due to a hypothalamic-generated satiety sensation which is caused by the perception of nutrients in the distal bowel. The intense distal gut stimulation reduces proximal bowel activity. The minimal postoperative nutritional complications after SASI bypass are attributed to the fact that the normal pathway of food is maintained, which aid in the absorption of minimal requirements of vitamins and other nutrients with less micronutrient deficiency (Salama et al., 2017).

According to the analysis of the BMI of the studied group of patients, the mean BMI was 48.7, which ranged from 39-54. Those results were near the results with
Santoro et al. (2012) who stated that the mean BMI was 42.9, and ranged from 3372. Our results showed agreement with results of Salama et al. (2017) who revealed that the BMI ranged from 35-56, and the mean BMI was 43.2.

As regard comorbidities distribution among studied patients, $40 \%$ of our patients were diabetics, $30 \%$ were hypertensive. As well, Mahdy et al. (2019) reported that $50.6 \%$ were diabetics and $36.1 \%$ hypertensive patients.

Glycemic control and lipid profile in our result, were in agreement with Abouzeid et al. (2019) who studied the effect of SASI operation on glycemic control of morbidly obese patients, and disfigured that complete remission of diabetes was achieved in $75 \%$ of the patients by the 3rd post-operative month, and in $95 \%$ by the end of the study. This was beside marked weight reduction and improvement of lipid profile without causing micronutrients deficiencies during the study period.

As regard BMI reduction during follow up, there was a high significant difference between before and after surgery. The mean BMI declined from 48.7 to $38,31.7$, at 3,6 , months follow up respectively. These results were in agreement with Salama et al. (2017) who stated that, mean BMI changed during one year follow up from 43.2 to 29.1. Also, Mahdy et al. (2019) reported those 12 months after the SASI, a significant decrease in the BMI was observed. From the aforementioned studies, SASI operation is an effective bariatric procedure in achieving weight loss at one year interval follow up. However, more patients, longer follow-up, and multicenter experience are 
all necessary to accurately figure out this procedure. Also, further studies on large geographical scale and on larger sample size to emphasize our conclusion.

\section{CONCLUSION}

The SASI bypass is an effective bariatric and metabolic surgery that achieved satisfactory weight loss and improvement in medical comorbidities, including T2DM, hyperlipidemia, and hypertension, with a low complication rate.

\section{REFERENCES}

1. Abouzeid M., Helmy M., Abdulaziz M. and El-Husseini M. (2019): Single Anastomosis Sleeve Ileal Bypass (SASI) for management of obese patients with type 2 Diabetes. Life Sci J, 16(11):112-120.

2. Andersson J. (2015): Laparoscopic surgery as treatment for rectal cancer. New England Journal of Medicine, 372 (14): 1324.1332.

3. Angrisani L., Santonicola A., Iovino P., Formisano G., Buchwald H. and Scopinaro N. (2015): Bariatric surgery worldwide. Obesity Surgery, 25(10): 1822-1832.

4. Augustin T. and Rogers A. (2017): Postoperative Management of ObesityRelated Diseases. In Bariatric Surgery Complications Springer, Cham, (pp. 65-76).

5. Carbajo M., Luque-de-León E., Jiménez J., Ortiz-deSolórzano J., Pérez-Miranda M and Castro-Alija J. (2017): Laparoscopic one-anastomosis gastric bypass: technique, results, and long-term follow-up in 1200 patients. Obesity Surgery, 27(5): 1153-1167.
6. Mahdy T., Emile S., Madyan A., Schou C., Alwahidi A., Ribeiro R. and Shikora S. (2019): Evaluation of the Efficacy of Single Anastomosis Sleeve Ileal (SASI) Bypass for Patients with Morbid Obesity: a Multicenter Study. Obesity Surgery, 30 (3):837-845.

7. Okereke E., Patil S. and Allred G. (2019): Airway and Respiratory System Damaging Events. In Catastrophic Perioperative Complications and Management Springer, Cham, pbl. 161-176.

8. Olmi S., Oldani A., Cesana G., Ciccarese F., Uccelli M., De Carli S. and Zanoni G. (2019): Laparoscopic One Anastomosis Gastric Bypass Versus Laparoscopic One Anastomosis Gastric Bypass with Braun Anastomosis: What's Better? Journal of Laparoendoscopic \& Advanced Surgical Techniques, 44(2), 551-565.

9. Salama T., Sabry K. and Ghamrini Y. (2017): Single anastomosis sleeve ileal bypass: new step in the evolution of bariatric surgeries. Journal of Investigative Surgery, 30 (5): 291-296.

10. Santoro S., Castro L., Velhote M., Malzoni C., Klajner S., Castro L. and Santo M. (2012): Sleeve Gastrectomy with Transit Bipartition. Annals of Surgery, 256(1): 104110.

11. Swanström L. and Beard K. (2018): Laparoscopic Approach to the Acutely Incarcerated Paraesophageal Hernia. In Minimally Invasive Acute Care Surgery, pbl. Springer, Cham, 25-32.

12. Tarek M., Wahid A. and Carl S. (2015): Laparoscopic singleanastmosis sleeve ileumbypass (SASI bypass): techniqueand preliminary results. Surg Obes. Relat Dis., 11:S56-S211. 


\section{نتائج عملية الأيض بعد عملية التكميم ذات الوصلة الواحدة بالأمعاء الاقيقة}

حاتم محمد المهدي، أشرف عبد الحميذ منعم، طارق عبد الكريم الدهان*، عبد الفتاح

$$
\text { مرسي سعيد }
$$

قسمي الجراحة العامة والباثولوجيا الإكلينيكية*، كلية الطب، جامعة الأزهر

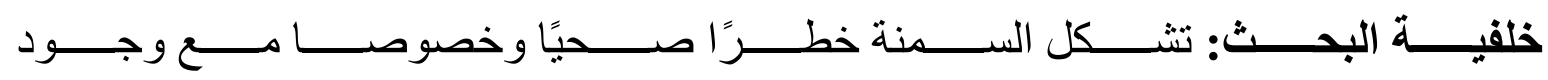

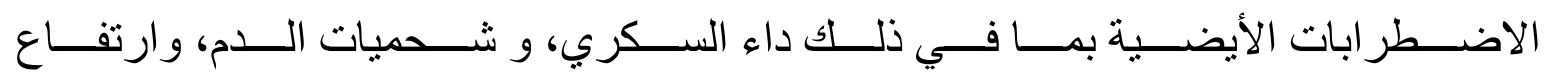

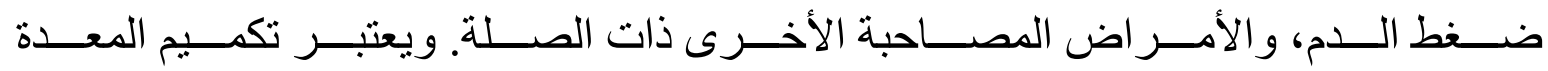

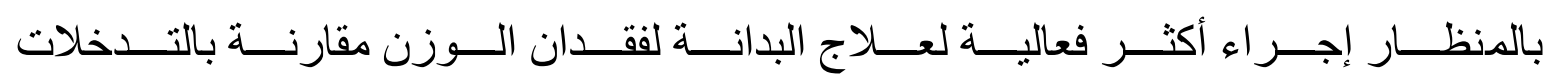

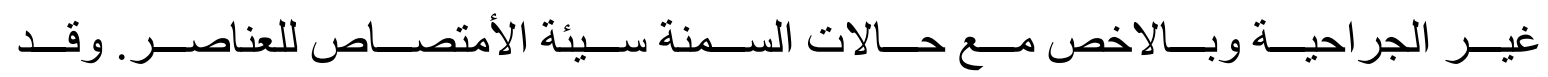

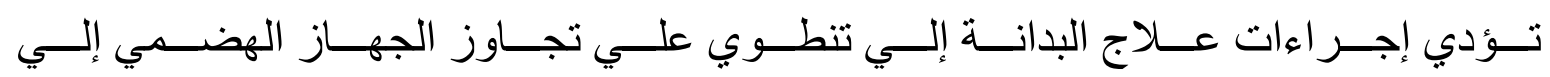

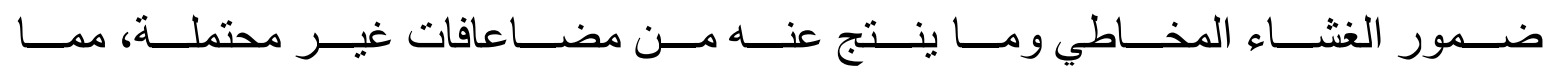
يدفع بدور للبحث عن حلول بديلة اقل تعقيدا.

الهــــف مـــن البحـــث: متابعـــة الأمـــر اض الأيضــــية مثـــال داء الســـكري وفــرط

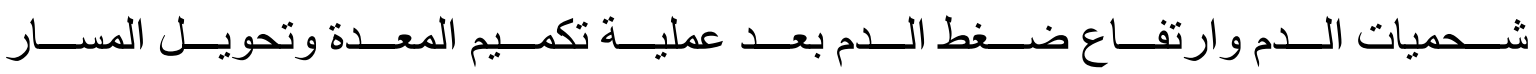

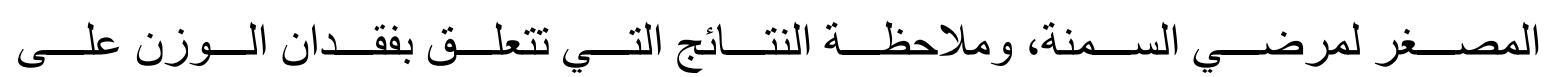
المدي القصبر وتقييم المضاعفات مثل سوء التغذية.

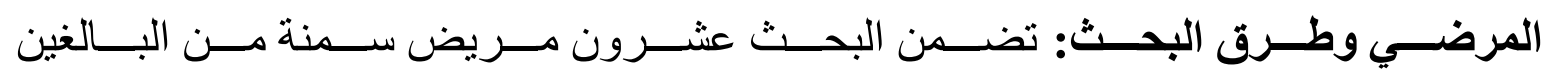

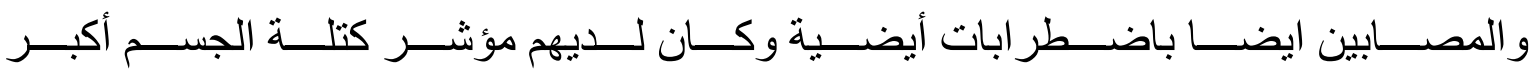

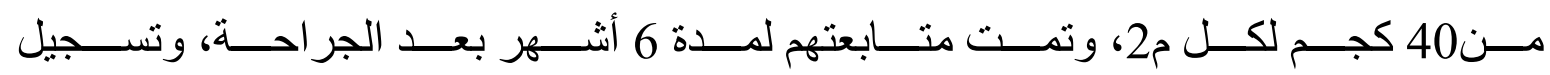

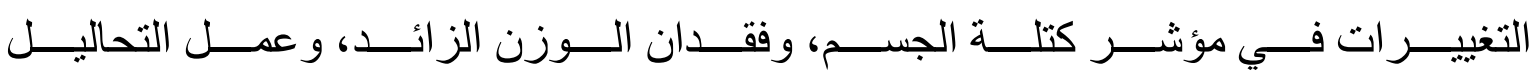

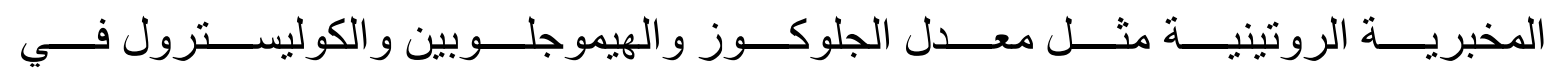

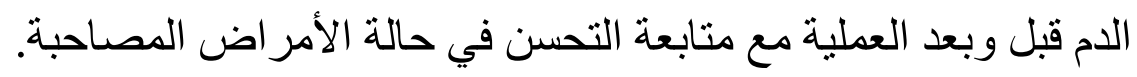

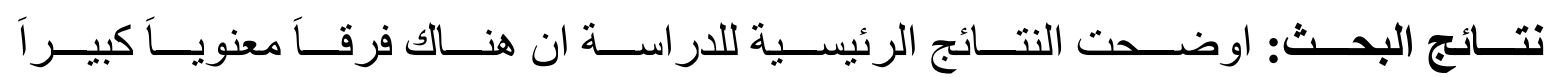

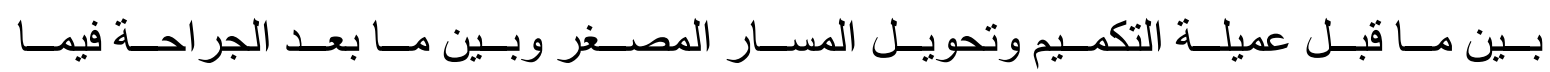


THE METABOLIC OUTCOME OF SINGLE ANASTOMOSIS SLEEVE...

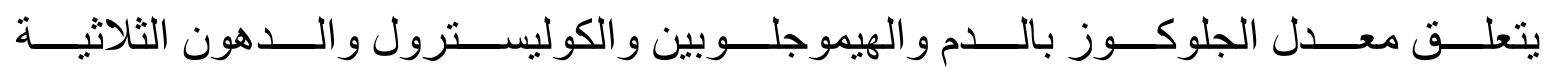

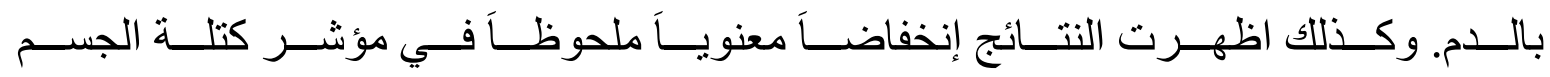

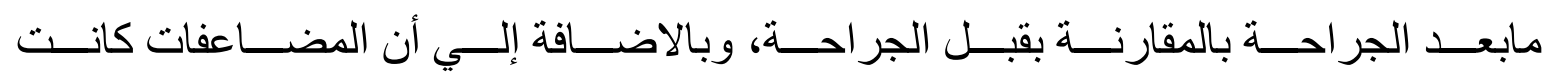

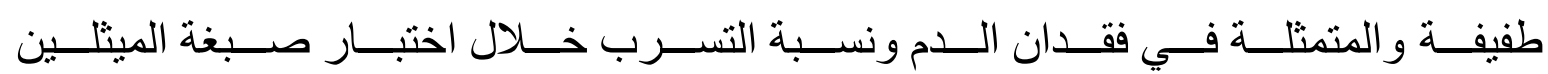
الأزرق لم تتجاوز ال5\% من الحالات.

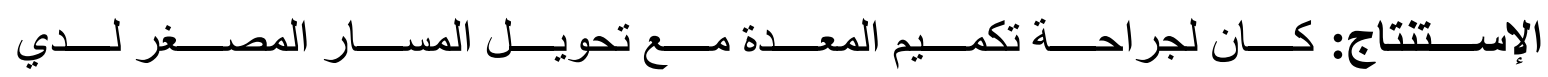

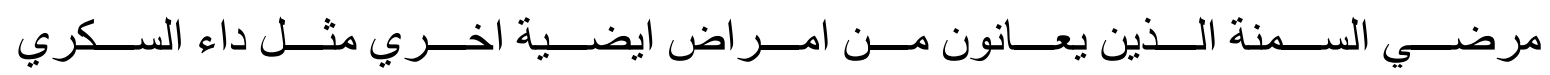

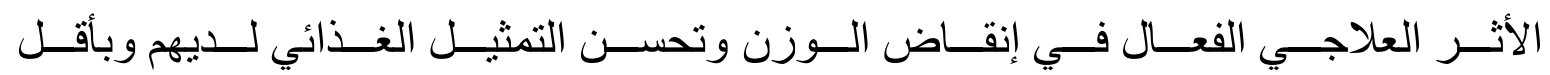
قدر من المضاعفات. 